\title{
Influencer marketing for museums: a comparison between Italy and The Netherlands
}

\section{Matteo Trombin* and Eleonora Veglianti}

\author{
Department of Economics, \\ University Uninettuno, \\ Corso Vittorio Emanuele II, 39-00186 Roma, Italy \\ Email:m.trombin@uninettunouniversity.net \\ Email: eleonora.veglianti@uninettunouniversity.net \\ *Corresponding author
}

\begin{abstract}
This paper is dedicated to the role of influencer marketing strategies in museums. In the last years, a range of time associated with Industry 4.0, studying the impact of influencer marketing in cultural contexts has become increasingly crucial. The digital technologies require businesses and the overall society to change. The purpose of the present work is to understand better the influencer marketing strategy applied to the cultural sector, such as museums, considering the universal and local features of the phenomenon. In particular, the study analyses and compares Italy and The Netherlands to verify that influencer marketing presents promising trends depending both from standard and local drivers. Through a research based on a qualitative data analysis (QDA), the present paper suggests a new way of analysing influencer marketing for museums, to investigate the aspects influencing its development and implementation. The methodology and results can be generalised to other cities and countries.
\end{abstract}

Keywords: influencer marketing; museums; visitor experience; engagement.

Reference to this paper should be made as follows: Trombin, M. and Veglianti, E. (2020) 'Influencer marketing for museums: a comparison between Italy and The Netherlands', Int. J. Digital Culture and Electronic Tourism, Vol. 3, No. 1, pp.54-73.

Biographical notes: Matteo Trombin received his Master's in Linguistics at the University 'La Sapienza' in Rome, with focus on Germanic Linguistics, and his Master's in Business Management and Digital Technologies at the University UNINETTUNO. He spent different research periods abroad, especially in The Netherlands, at Utrecht University, and in France, at Lille University. He collaborates with both Italian and foreign universities. $\mathrm{He}$ currently works as export consultant. He is an author of a number of scientific and dissemination papers on different topics, such as: on the one side e-HRM, smart city, novel technologies applied to business strategies, innovation management; on the other side, Dutch linguistics and Italy-Low Countries cultural transfer, with particular reference to the 17 th century.

Eleonora Veglianti received her $\mathrm{PhD}$ in Economics and Management, University of Perugia, Italy. She received her Master of Science in General Management from the LUISS University in Rome, spending one academic year in Fudan University, Shanghai, China. She collaborates with several universities both Italian and foreigner. She spent different periods abroad to collect data for her researches and she has an expertise on China. She was a Visiting $\mathrm{PhD}$ student in the Wuhan University, in China. She teaches 
Accounting and Business Administration in the University of Uninettuno, Italy. She works as a strategic consultant in a private company. And also a member of the mentoring program in LUISS University in Rome. She is an author of a number of scientific papers about different topics, such as: industrial economics, network analysis and consumer behaviour.

\section{Introduction}

Digital technologies have been influencing and permeating every aspect of society. Traditional organisations are tasked with the successful adoption of new tools to survive, and cultural institutions do not make the exception. The use of digital tools and new marketing strategies become necessary, but they can be just an enhancement of the peculiar experience and engagement cultural organisations already represent to the visitor. Consequently, social interaction becomes increasingly essential also for building and strengthening relationships with all the stakeholders involved: government, municipality, tour operators, the Hotellerie-Restaurant-Café (HO.RE.CA.) sector, private citizens affected by the impact of growing tourist fluxes, etc. (see, e.g., Zardini et al., 2014).

Social data analysis covers a wide range of experiential items that, in addition to influencing the choices of future travellers, could be very useful to understand the actual quality of the visit, the strengths to be exploited and the weaknesses to work on (Manetti, 2011).

On the one hand, cultural tourism has registered significant expansion in recent decades, fostered by a growth in the levels of citizens' income and education but public budget devoted to museums in Europe is narrow. Today, cultural tourism has become a valuable resource for European countries, particularly those with abundant cultural heritage, as is the case in Southern European countries such as Portugal, Spain, Italy and Greece (Arostegui and Rius-Ulldemolins, 2018). On the other hand, two significant issues impend: touristic polarisation in the most visited areas exacerbates competition among museums.

Visitors tend to concentrate in a limited number of destinations, and Europe is becoming a less cultural continent as fewer Europeans are engaging in cultural activities, so the problem of non-participation legitimates a solution that predates its emergence: the state subsidy of arts organisations (Stevenson et al., 2017). State subsidies are not consistent, however. Museums need additional revenues to stick to budgets: engaging with new marketing tools to build their brand image, and to replenish the coffers. This paradigm shift of museums towards visitors and experience has led to the prominence of a museum marketing approach, determining a revolutionary impact on museum practices (Ferraro, 2011).

Traditional advertising and communication tools have too high costs and are univocal, addressing an indistinct mass. Content produced and conveyed by influencers is much cheaper, self-nurturing, and audience-targeted. As technology gets cheaper and cheaper, while accruing its potential, individuals like influencers can access technological tools more quickly and efficiently, so they can generate more added value for market and followers. For this reason, museums try to harness influencer marketing to their goals. As 
an example, this leads to influencer market monitoring: influencers personally take their pool of followers into their everyday lives and influence consumer behaviour.

From a cross-analysis of various sources (theoretical literature, websites, social media, blogs, official reports, and statistics), it emerges that the general aspects to all museums at the global level have never set apart from the specific features distinguishing every region/country. Moreover, the literature is scarce in this field of investigation, no papers address the different influencer marketing path in comparison between different countries taking into consideration the international and the local implications in the meantime.

In line with this, the present work aims to understand better the influencer marketing strategy applied to the cultural sector, such as museums, considering the universal features of the phenomenon and problems, together with the local and specific aspects influencing its implementation. Consequently, the research questions are the following: How does influencer marketing for museums work in different countries? What are the main differences/similarities in its implementation?

To answer these research questions, a qualitative research was conducted, based on a theoretical framework applied to a comparison between influencer marketing strategies and implementation in different countries. Therefore, two countries - Italy and The Netherlands - were selected within the same framework (the EU), which show many similarities, just as many differences.

The choice of Italy and The Netherlands is also the consequence of the nationality and of the involvement of the authors in these countries. In addition, their deep knowledge on the local literature and documentations about the subject in original language, without the filter of the translation results an important aspect in studying the materials as well as in enhancing the tacit knowledge of the culture of a specific country.

The rest of the paper is structured as follows. Section 2 presents the literature review; Section 3 describes the research methodology and steps; Section 4 defines the process of the research, theoretical insights and empirical evidence to highlight the emerging features of influencer marketing in Italy and The Netherlands. Finally, Section 5 concludes evidencing the findings, presenting the limitations and suggesting further works.

\section{Literature review}

In the last years, a range of time associated with the 'new economy', the business model (BM) has become increasingly crucial in many research fields, changing the overall society with the scope to make sense regarding 'doing business' (Osterwalder et al., 2005; Zott et al., 2011).

During the digital era, new opportunities to create value emerged in different sectors. Following this perspective, in the age of revolution, all kinds of organisations need to develop new BM strategies, in which both value creation and value capture come out in a value network (Hamel, 2000).

In this scenario, also the cultural heritage sector has to take into account that can no longer confine itself in a conservative BM; while, it has to develop new strategies to promote an innovative supply tailored on the needs of the today's users and, thus, to attract a growing audience (see also Ercolano et al., 2018). This paradigm impacted the 
usual approaches (i.e., in advertising and communication) towards new tools which address the experience today's customers (i.e., visitors of a museum) are looking for.

In line with this, new marketing strategies, especially the so-called influencer marketing, has a growing impact on the value chain and, consequently, in the final performance of a museum.

From the academic point of view, only some sprinkled points can be drawn from general theoretical works. As far as the authors found, little or no specific research was devoted to influencer marketing strategy applied to museums. Other (often private-led) sectors, such as fashion, lifestyle, and cosmetics, can count on a more consistent, although inchoative, research (see, e.g., Zietek, 2016; Glucksman, 2017), due to pioneering marketing experimentation triggered by business competition.

The topic pertains to the broader range of literature covering general influencer marketing strategies (Sammis et al., 2016; Woods, 2016; Nirsch and Steinberg, 2018), brand perception and construction driven by influencer marketing (De Veirman et al., 2017), risks of covert advertising and deceptive practices linked to influencer marketing (Gürkaynak et al., 2018; Bladow and Mary, 2017), impact and effect of influencer marketing upon user engagement and behaviour (Jaakonmäki et al., 2017; Johansen and Guldvik, 2017; Ewers, 2017).

The exciting feature is that many of these works are not scientific contributions, but most of them are non-conventional literature. This feature turned out to be useful to unravel the tangle of definitions and approaches, since influencer marketing, as a relatively new term, has no academic definition. However, the definition of influencer marketing undeniably proceeds from the concepts of credibility and clout. Cialdini's $(1998,2007)$ and Cialdini and Goldstein (2004) principles of persuasion and influence (reciprocity, consistency, social proof, authority, scarcity, and liking), can be adapted to the digital and interconnected world, meaning they boost conversations in online marketing (Ioanid et al., 2015).

By consistently creating content and building a relationship with their followers, influencers gain the trust and confidence of those who follow them (Woods, 2016), and the product they are placing in a post seems authentic even though it is known they are receiving compensation. According to the Nielsen (2015) Global Trust in Advertising Survey, two-thirds of consumers trust the opinions published online.

The compelling need of targeting ads on social media platforms such as Facebook or Instagram is fostered by the use of influencers, since this way it is possible to identify receptive audiences that are less likely to click on a pitch or banner of pure sales, instead are more willing to hear catchy 'stories' and to co-create them. In this way, the experience museums create needs to be linked to the experience people want and a new narrative to attract younger audiences.

Experiential marketing applied to museums is an entirely explored field (Kolb, 2000; Prentice, 2001; Petkus, 2004; Kirezli, 2011). When applied to museums, this concept means participation, which is experienced with a sense of belonging, coherence, and involvement with oneself and one's own world of values.

Social media are pivotal in creating this identification. Instagram, due to a steadily expanding audience and visual potential, has become a vital tool for arts and a growing number of museums includes it into an overall social strategy (Sallami, 2018). For this reason, some scholars tried to investigate the relationship between Instagram and museums, highlighting and developing all these points (Weilenmann et al., 2013; Abidin, 
2014, 2016; Budge, 2017). Based on the most recent developments in research related to social media and museums, also visitors were classified and subdivided into clusters, having different impact, behaviour, and reception of marketing strategies adopted by museums.

For example, Gross and Wangenheim (2018) have lately identified four distinct types of museum visitors: snoopers, informers, entertainers, and infotainers. In their study, temporal dynamics and influencer type transitions based on social presence and domain breadth are shown to provide a guideline for companies to successfully scout influencers. Also, influencers have been classified in several ways: a more neutral distinction is recognisable for example in Platteeuw (2018) between micro-influencers, influencers, and top influencers; a categorisation by archetypes is to be found instead in Barry (2014), who identifies the educator, the evangelist, the motivator, the mentor.

Furthermore, from the literature, though, no structured formula for defining influencer marketing for museums emerges, although single facets of the topic were fathomed, and more general definitions of influencer marketing were drafted.

Nonetheless, one should take into account that definitions change at a swift pace. For instance, Duong (2017) definition was slightly modified, substituting, e.g., the word 'buyers' with 'customers', so clearly affirming the strategic and planned customer-oriented approach, based on the updated literature about the topic.

Based on the relevant literature and on the shrewd assumption that influencer marketing can be partly rationalised by two already existing theories; word-of-mouth (WOM) and opinion leadership (Johansen and Guldvik, 2017), and based on the fact that micro-influencers have outnumbered macro-influencers entering 2019 (Hellenkamper, 2019; Settels, 2018), a tentative definition of the influencer marketing applied to museums is presented in the present work. Influencer marketing for museums can be regarded as the use of (micro-) celebrity endorsement sustained by socially recognised online authority, aimed at promoting the cultural experience embodied by museums: this goal is achieved by sharing transparently sponsored content on influencers' own social media channels (mainly Instagram), as well as by linking a personal cultural experience to an emotional feature characterised by authenticity, which leads to cultural consumer's engagement and identification.

Influencer marketing strategy for museums can supposedly be defined as the same marketing mechanism applied to museum system branding or city branding for tourism (for the last one, see, e.g., Lollo, 2018). In conclusion, influencer marketing and the cultural sector seem to be a match made in heaven (Van den Elsen, 2018).

\section{Research methodology}

The research methodology is the result of depth qualitative approach, which includes both theoretical and empirical pieces of research and activities (Yin, 2013). Qualitative data analysis (QDA) is applied in the current paper, to understand how economic, political, social, cultural, environmental factors influence the social aspects of influencer marketing in natural settings (Mays and Pope, 1995).

The aim is to describe the influencer marketing situation with no pre-defined response categories, drawing out patterns from concepts to achieve conclusions. Therefore, the research questions are broad, and the expected outcomes are not identified previously, while further insight is obtained through data collection and analysis (Hammersley, 
1997). Here, the QDA design is based on grounded theory (Corbin and Strauss, 1990; Glaser and Strauss, 2017); following the suggestions of Turner (1981) to elaborate theory from data.

In line with the relevant literature on this approach and the aim of this research, different types of qualitative data are used to have a better understanding of influencer marketing to discover theory. Following this reasoning, data on several sources are collected, to highlight the impact in a natural context. In fact, on one side, there are structured texts, such as scientific papers, books, and reports. On the other side, there are unstructured texts, such as transcription of speeches, articles, and blogs. Then, an inductive approach is applied.

The QDA presents the following five steps: organise the data; identify framework; sort data into the framework; use the framework for descriptive analysis, and second order analysis.

Firstly, qualitative data are collected and organised; this step is mainly described in Section 4. Then, all the materials have been analysed several times, to define a QDA exploratory framework, guided by the emerging patterns about influencer marketing. This step is described in Subsection 4.2, and it determines the theoretical framework under investigation. Features are then used to code the data, applying the emerging labels to text (Seidel and Kelle, 1995) to investigate about the specific elements of influencer marketing in Italy and The Netherlands (described in Subsection 4.3). The outcome of the first four steps represents the input for the second order analysis, to interpret repetitive patterns regarding the topic under examination (Bryman and Burgess, 2002). Results of the QDA final steps are shown in the following Subsection 4.4.

\section{QDA: process and findings}

\subsection{Data collection and analysis}

Since the topic is only partially explored in the literature, the choice of methodology was made on a mainly qualitative basis from a plurality of sources following the scope of the paper in creating a theoretical framework. The analysis supporting the present article is made by a broad level activity, both looking at the theoretical and empirical sphere (Bryman and Bell, 2011). In line with this, the selection of more than two countries would represent a too vast and maybe too entangled subject to depict in a pioneering paper.

This article highlights the differences between the theoretical vision and the practical implementation of influencer marketing. Besides, the analysis of Italian and Dutch influencer marketing in museums supports the research hypothesis, showing that the local aspects are crucial in defining the marketing initiatives and their implementation. Therefore, the authors preferred to study only two countries with the purpose of future contributions which apply the framework in different contexts.

The selection of these two countries (Italy and in The Netherlands) was guided by the following reasons: first, the authors can read and analyse the overall material - both structured and unstructured texts- in the original language which was crucial to build the theoretical framework presented. In other words, the article includes various sources both structured and unstructured texts, specifically: scientific papers, documents, reports, web sites, blogs, interviews, and conferences' notes that required in-depth knowledge of the 
language. Thus, the goal of the paper is two-pronged: on the one hand, it was necessary to funnel the current assorted literature in order to setup a valid definition of the terms; on the other hand, the same literature, if coupled with data, was useful to compare two peculiar national cases, Italy and The Netherlands. Second, in this way, the authors avoided possible mistakes due to the translation done by a third party. Then, the knowledge of both languages, as well as the direct experience in these two scenarios improves the investigation helping, in general, a deeper understanding of these two contexts and, specifically, a better examination of the influencer marketing field.

Moreover, these two countries were interesting to study because even within a common context (the EU) they have peculiar background differences such as The Netherlands have a disruptive and mature approach to the influencer marketing theme in various fields as well as applied to museums; while, Italy presents a less developed approach even with the presence of the largest cultural heritage of the world. Following this, it is interesting to analyse two different scenarios in managing their heritage, considering the introduction of new marketing tools.

To compare these two countries, the literature of the second part of the 2010s is taken into account, since it is a topic evolving very fast; however, what had been written before that date was assumed useful to define the general framework only. The data collection was repeated several times to reach a more precise framework that goes from a broader to a more detailed level of analysis. This exploration leads the authors to identify the following distinctive features of influencer marketing in the museum. Consequently, the model is composed of:

1 interaction

2 creativity

3 visual popularisation

4 cultural newsjacking

5 performative approach.

\subsection{The theoretical framework}

The second step of the analysis defines the theoretical framework (Figure 1), driven by the emerging patterns of influencer marketing in the museum from both a standard and local point of view. From the analysis of domains and dimensions, the following factors were identified:

1 Interaction: This term encompasses a more emotional relationship with brands and products. The peculiarity with influencer marketing for the museum is that the level of interaction is direct, with micro-influencers, often hitting the mark and representing a more successful strategy than macro-influencers; also, there are dedicated platforms aimed to connect supply and demand of influencer marketing for museums seek to achieve this goal.

2 Creativity: This feature derives from the emphasis, in this peculiar sector, on the personal expression rather than on functionality and efficiency. The content of museums is perfectly fit for beautiful images, a relatively low investment ensures an extensive outreach, and cultural consumers share the content. 
3 Visual popularisation: In order to act upon the brand awareness of the museum, it is compelling to convey the values of the museum via simple digital languages, closer to the reference target. Influencers play a crucial role in realising branded content. Thus, a perspective change in cultural communication is needed in order to break through complexity and bridge the generational divide.

4 Cultural newsjacking: 'Newsjacking' is a marketing technique aimed at increasing the popularity of a brand through social networks, then having advertising at a minimal cost, by merely hooking up-to-date news. It is, therefore, a real-time marketing process through which one's brand is inserted into the flow of daily news, creating something that captures the attention of users. This process also applies to the cultural sector, provided the newsjacking meets several specific requirements.

5 Performative approach: This feature can be seen as a general framework of visual art performativity, and it harks back to the linguistic concept of performativity (see, e.g., Austin, 1962; Searle, 1969; Lyotard, 1984) applied to visual art: a visual language mediated by social networks becomes a language that actually describes the world but may instead (or also) function as a form of social action. As a social activity, it also affects the related policies, implemented by the public body a/o the museum institution/system.

Figure 1 The theoretical framework (see online version for colours)

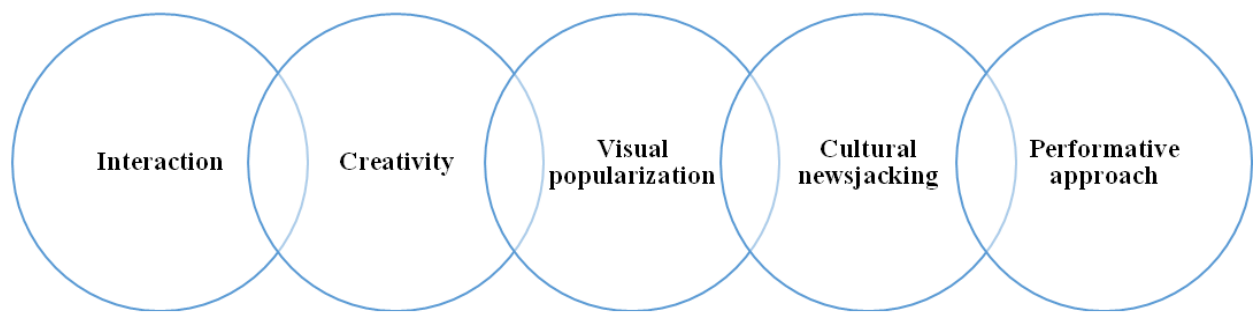

\subsection{Influencer marketing for museums in Italy and The Netherlands}

This paper compares two countries belonging to the same geopolitical context (the European Union), thus starting from the same pre-conditions. Data indicate that Italy has 4.026 museums, galleries, and collections (public plus private) gathering 57.8 million of visitors as of 2017, with only three regions (Latium, Tuscany, and Campania) absorbing $52.1 \%$ of the visitors. The majority is managed by municipalities but also provinces and regions (ISTAT, 2016).

While, The Netherlands has 1,100 museums (public, plus private), with 39.5 million of visitors. Out of these, Amsterdam alone (850,000 inhabitants) comprises 66 museums with an average of 12.5 million visitors a year (AdresData, 2018).

\subsubsection{Italy}

The case of Italy is unique; then it represents a valuable starting point to explore the complexity of any heritage-related research. In fact, according to last available Eurostat data, Italy is third-last in Europe as to government expenditure devoted to recreation, 
culture and religion (with a meagre $1.7 \%$ as of 2017 - EU average being $2.3 \%$ ), a percentage, which has shrunk over the years, according to latest EUROSTAT data, as of 2019. Also, though, Italy is deemed to comprise between $60 \%$ and $75 \%$ of the world heritage, with the highest number of UNESCO world heritage sites.

Most of all, Italy's heritage is widespread, often scattered across a fragile and not easily reachable land. Nonetheless, according to US News World Report (US News, 2019), Italy is still ranked first in the Cultural Influence Ranking, which lists the trendsetters in the cultural sector, intended as a whole, and in the Heritage Ranking, due to its many artworks.

In numbers, Italy has a dispersed heritage scattered across the entirety of the land, counting 1.6 museums or similar institutes per $100 \mathrm{~km}^{2}$, and about one museum every $12 \mathrm{k}$ inhabitants.

Considering the last official statistical data as of 2017 of the Italian Institute of Statistics (ISTAT), the regions with the highest number museum structures $(29 \%$ of the total) are Tuscany (528), Emilia-Romagna (482) and Lombardy (409). In the South, more than half of the archaeological heritage is located (50.8\%), 30.7\% of which is to be found in Sicily and Sardinia.

Moreover, the number of visitors has steadily increased since 2013, from 38 million to an average 58 million $(+31 \%)$ and revenues have increased by 70 million of Euros $(+53 \%)$ (ISTAT, 2016).

In conclusion, in the Italian context, areas with the highest number of museums or with a specific target of museums do not match the most visited areas. Museums need to compete in a complex environment both on a national and international scale. In this scenario, social media results a valuable tool for improving performance, and influencer marketing is becoming an integrating part of the overall marketing strategy.

\subsubsection{Interaction}

Regarding the interaction dimension, there is an improvement from the point of view of the presence of the Italian museums on these channels. For example, 57\% of Italian museums today use these channels to communicate and create engagement and brand awareness. If we take a look at the most used channels in the period 2017-2018 in comparison with the previous years, we note that Facebook remains the most used channel, in a year, goes from 51\% to 54\%; followed by Twitter, still loved by Italian museums, especially the larger ones, recording a growth of $3 \%$, similar to that by Facebook. However, the channel that records the highest level of use in a year is Instagram, which goes from $15 \%$ to $23 \%$, with an increase of $8 \%$.

In other words, Instagram grows in use related to museum communication. This is a popular, although recent, phenomenon, which is more or less leveraged by Italian museums, depending on leadership and target.

An interesting example in this case is the National Gallery of Modern and Contemporary Art in Rome (GNAM) that organised many social initiatives, the most important of which was \#emptymuseum in 2016, involving one of the most important influencers of the sector, namely Firpo (2015) (59 k followers on Instagram) and many other micro-influencers. Through this initiative, the following numbers were registered: +2.259 on Twitter, +1.418 on Facebook, and +190 on Instagram, in comparison with 2015 (Pecorelli, 2017). 
As a consequence, the same happened with the posts on the social networks by the account holders of the museum, passed from 2.809 of 2015 to 7.165 of 2016. The two-day initiative, with the hashtag \#EmptyLaGalleria, had 135 Candidates, 24 Igers (participants), 215 posts, 204 pics, three videos. The initiative \#Time is out of joint in 2017 reached even brighter deliverables, included in a report published on Issuu.com.

\subsubsection{Creativity}

As to the second factor of the framework, the Italian experience has followed international experiences but also found some peculiar strategies. For instance, the American photographer Dave Krugman launched in 2013 the international movement \#Empty, cited above. The idea was to disseminate a unique outlook upon the cultural spaces, by showing them when they get empty in the evening and artworks remain secluded. Only a few Instagrammers attend, each one with his/her pool of followers. The initiative was warmly welcomed worldwide, and it was in Italy, too.

Besides the case of GNAM, also the Duomo of Florence, the palace of Venaria Reale in Turin, the Prada Foundation in Milan and, more recently, the Scuderie del Quirinale in Rome performed the initiative. The latter \#EmptyScuderie drew the attention of more than 100 influencers of Rome, who allowed to bring the official hashtag of the event among the social network trends of the Twitter microblogging.

Among the owns way initiatives, the aforementioned GNAM created in 2019 Mimmoflow with the hashtag \#TAPTHEEXHIBITION, covering more than 150 Instagram Stories, embedded in a perfect puzzle of millions of pixels in 16/9, composing the display of the exhibition Mimmo Rotella Manifesto, online from 8th February 2019, on the Instagram profile @lagallerianazionale. Again, the GNAM launched in March 2017 \#SCROLLTHEEXHIBITION, the first exhibition worldwide on Instagram, with a mosaic of 150 posts of the Museum Beauty Contest, contrived by the Spanish artist Paco Cao.

\subsubsection{Visual popularisation}

Visual popularisation means primarily the creation of new communication languages aimed to 'tell' an exhibition, to appeal to a broader, often younger, audience, to debunk and demythologise a complicated art language/place, considered as old, inaccessible and not 'cool'. In Italy, the Archaeological Museum of Naples chose in 2018 the support of the renowned Neapolitan debunking and ironic video makers The Jackal (millions of views on YouTube, $690 \mathrm{k}$ followers on Instagram).

The choice was even more daring because their debunking approach was associated with a traditionally stern world, as archaeology is. Indeed, the video (reaching 2 million views) not only makes fun of the snobby world of culture but also of the way culture is communicated, by parodying a famous Italian disseminator, namely Alberto Angela.

The goal of the museum was actually to broaden the fruition, by targeting the audience 18-30, which is the one The Jackals appeal to the most. This initiative was successful. Though, it did not have a follow-up and communication has been stagnating onto the old patterns. The same goal was to be achieved in 2017 by the Municipality of Bologna, which aimed at increasing the number of very young users of the Museum Card Bologna through a different narrative language. Here is the reason why Museum Card 
Bologna decided to rely on a very young YouTuber, Luis Sal, also reaching 1.1 million followers on Instagram.

To get closer to the audience, target 13-24 years old, the agency Profili, which follows the communication of the card, chose to change the language. Luis Sal was asked to create three ad hoc videos. The final result was more than 370,000 views on all platforms, of which $80 \%$ on YouTube, $+400 \%$ interactions on YouTube and $+262 \%$ on other channels, with a significant increase of subscribers on all platforms, but above all the presence of the public from the 13 to 24 years for a total of $62 \%$ compared to the total audience in the three weeks of the campaign (Profili, 2018).

In addition to the 'classic' dissemination of the content, three Instagram stories were created, published one after the other within 24 hours. This operation brought more than 2,500 views of the original video.

\subsubsection{Cultural newsjacking}

Cultural newsjacking can be planned or improvised. Whatever the strategy adopted, the key element to be effective is the timeliness for intercepting topics on the agenda. The right irony and the necessary coherence between the news and the values perfectly match the peculiarities of influencer marketing for museums. An example of effective cultural newsjacking on a planned basis is the museum Poldi Pezzoli of Milan, which implemented a newsjacking campaign linked to the release of Star Wars episode 7 in 2015 by putting the characters of Star Wars into its artworks. Also, some micro-influencers have been adopting this kind of technique for promoting the MAXXI museum in Rome.

\subsubsection{Performative approach}

In Italy, the social media manager is present in $59 \%$ of institutions as embedded in the museum, in $26 \%$ of museums as third-party. Regarding the online presence of about 500 Italian museums, a slight increase can be noticed in the number of cultural institutions with a proprietary website ( $43 \%$ compared to $42 \%$ last year) and progress is recorded on the front of services made available (Russo, 2018).

From the point of view of innovation and activated projects, the research finds that only $39 \%$ of the institutions participating in the Community have a formalised strategic plan and $19 \%$ a digital innovation plan. Communication is the sector that more than others is at the centre of innovation in Italian museums $(72 \%)$, followed by fruition (64\%) (Russo, 2018). There is a lack of strategic focus on the theme of long-term digital preservation and digital asset management, approaches that are instead described as trends of the future by experts in the sector, also using emerging technologies such as blockchain (Osservatorio, 2018).

In 2016, the Italian Ministry of Cultural Heritage (MiBac) collaborated with the agency Travel Appeal, in order to work out the Travel Appeal Index Score (TAI Score), pointing out the digital positioning of a museum, which has increased by seven points averages. The index takes into account several parameters, among which the general visitor satisfaction; the visitor's perception of welcoming, activities, events, services and spaces; the awareness; the rate of responsiveness in the use of social networks on behalf of the museum staff; usability and accessibility; etc. (Stroia, 2016). 
The GNAM is among the few Italian museums with a particular form of autonomy, from the scientific, financial, administrative, and organisational point of view. Actually, its status meets the need of managing it flexibly, dynamically, and with innovative tools. The relationships with stakeholders like institutions, local communities, businesses, and private citizens are favoured by that structure. Revenues come from tickets, from a loan fee system and the relations with private investors (Galleria Nazionale, 2019), employing sponsorships, rent-a-space, Art Bonus (provided in accordance with the pertinent Ministry).

Based on the peculiar condition, the GNAM operates a marketing strategy aimed at enhancing the relationship with private actors, developing the cultural synergies and creating regional networks. In this framework, also co-marketing agreements are envisaged, with local public bodies (like the integrated touristic circuit of the Municipality of Rome), but also with foreign private investors like Air China, which is situated in an overall strategy of engagement of Chinese tourists, supported by other initiatives.

The GNAM is first for overall visitor satisfaction with $91.7 \%$ of positive sentiment. All other museums have a score between 64 and 91\%. Among the positive sentiment bands, the most populated is represented by the Museums between 81 and $89 \%$ of overall satisfaction (Stroia, 2016). The way paved by the GNAM and other top Italian museums with a balanced governance and hybrid management can be considered the path to follow towards a more systematic management of the museums, which seems to lack of coherence, although the awareness of a more thorough approach was manifested in the Extraordinary Plan for Touristic Mobility 2017-2022, issued by the Ministry of Infrastructures, towards a national smart destination plan.

\subsubsection{The Netherlands}

It is interesting to investigate The Netherlands and to compare it with Italy, since The Netherlands is first worldwide in the ranking of Business sophistication, according to the Global Innovation Index 2018. It means that innovative tools and new hybrid solutions are applied to the cultural sector with a cutting-edge and pioneering approach, linked with a new narrative and visual interactive storytelling experiences.

This also led to extensive experimentation of value co-creation of museum experience design (Vermeeren et al., 2016; Navarrete, 2014). Also, what is more interesting is that the Dutch innovation strategies deploy in a peculiar system of public governance, which is historically deemed different from Anglo-American 'managerialism' (Kickert, 1997).

There are 28 museums in 2016 that receive subsidies from the Ministry of Education, Culture, and Science (CBS, 2016). They manage items from the national collection and receive a subsidy for public activities and the preservation and management of the collection. The majority of the museums receive a subsidy from municipalities; there are also museums that are exclusively financed privately. Museums display their permanent collection but also organise temporary exhibitions in their museum, or a museum elsewhere. The expected number of visitors to museums in The Netherlands increased slightly in 2018 to 39.3 million (AdresData, 2018).

For some museums, the target group between 20 and 40 years old is still the most important. A museum like Moco Museum in Amsterdam is about to launch an interactive app that allows visitors to take exclusive photos in order to be attractive so that the visitor can see the result in his/her timeline on Instagram (De Smit, 2018). Since Dutch 
museums aim at creating a consistent flow of conversation with visitors, social media are pre-eminently the place to start this conversation with whom will become their followers and fans.

Nevertheless, the rate of responsiveness and social media direct interaction is not that high among museums, but the rate of responsiveness and social media interaction match the museums of the above list, which had the most valuable increase in visitors.

For instance, the aviation theme park Aviodrome in Lelystad adopts responsiveness as a strategy: the potential visitor's questions are always replied, also when someone responds enthusiastically. In this way, Aviodrome is building a community with really enthusiastic fans, who can turn into brand ambassadors in the long-term.

Also, in The Netherlands, a couple of platforms exist, which aim at connecting supply and demand of influencers, with sub-sections devoted explicitly to influencer marketing for museums. For example, the platform Join (2019) argues that the most critical goal of influencer marketing is reaching a specific target audience that is located in a niche, and museums actually are a niche, which moreover is fit for influencer marketing: even though museums are mostly silent, they should spark discussion and get many people talking, thus creating engagement.

\subsubsection{Creativity}

In order to mould the visitor of the future, cultural organisations are taking the first steps on disruptive techniques. In 2016, the Stedelijk Museum of Amsterdam already used influencers to attract a younger audience for the exhibition by Isa Genzken. Various museums organise instameets, in which Instagrammers with many followers and affinity with art receive a preview of the exhibition and share it.

Museums also invite influencers more often to view exhibitions and to photograph them before they are open. Mick Groeneveld from the Tropenmuseum does the same. Often, Dutch museums tend to create spaces to photograph, and to compose spaces based on the degree of possible instagramability, creating 'instamuseums', which are purely focused on Instagram, without having their own collection, but making unique works and rooms focused on this medium, following the model of the United States, even though this phenomenon is not as widespread in The Netherlands as it is in the USA.

For example, the Cool Japan exhibition in 2017, the Tropenmuseum setup a particular room for selfies. While the Moco Museum is also experimenting with visually attractive corners that art-loving Instagrammers like to share.

\subsubsection{Visual popularisation}

In The Netherlands, it is also well established the role of the 'kunstbloggers' and 'kunstvloggers' (art bloggers and vloggers). The second ones, in particular, make use of videos replacing the written word in narrating passions, experiences, and emotions related to the museum space. An example is the culture vloggers 'My daily shot of culture', who kicked off the disseminating and evangelising initiative Thirty Shots, jointly with the marketing agency Buro Dertig.

The first edition of Thirty Shots took place on 24 April 2018. The second edition took place on 29 November 2018. Another example is the Chinese 'kunstvloggers' Hongjia Liu and Yuxi called for the exhibition 'Through the wall' in the museum Voorlinden in 2018. Based on the fact that museums have fascinating stories to tell, Gemeentemuseum 
Den Haag integrated visual storytelling with anecdotes highlighting details of the exhibitions or showpieces by telling a story.

\subsubsection{Cultural newsjacking}

The practice of cultural newsjacking is planned in the case of Museum van Loon, which combines the announce of a brand-new exhibition with International Women's Day and other important and significant dates, mixing peculiarities, news, and perfect timing. Another case is that of DAF Museum, hosting exhibitions of the trailer factory DAF in Eindhoven. They usually jack news about the motor sector and sports.

\subsubsection{Performative approach}

A successful social media strategy is not only reserved for major players such as the Rijksmuseum and the Van Gogh museum. It successfully applied also to relatively less well-known museums, which have an enormous online potential that has not been fully harnessed. It is significant that out of the 2700 contacted persons belonging to the 1100 museums scrutinised by AdresData (2018), 384 pertain to the Department Marketing and Communication.

Year after year, Dutch museums pay more attention to making a strategy, and integrate different types of content forms into it, trying to engage in conversation with fans who would respond enthusiastically proactively.

An example of integrated strategy becoming BM is the case of Eindhoven365, which is the official city marketing organisation of the city Eindhoven, which incorporates influencer marketing for museums as a strategy to develop an integrated strategy aimed at spurring tourism to the city of Eindhoven, which is a city of transit, due to the very well patronised airport of Eindhoven, this is achieved by leveraging city branding and a welloiled logistics network (EHV365, 2016).

\subsection{Comparing Italy and The Netherlands: emerging results}

By analysing the two countries, based on the five factors of the defined theoretical framework, both similarities and differences emerge. Regarding the similarities, the following ones can be highlighted:

- Creativity: Well-established events in both countries are instameets. An instameet consists of a group of Instagrammers who meet to share experience, shoot pictures and record a video together, with no restrictions as to agreed place and number of participants; a standardised sub-case is \#empty events: a group of Instagrammers meet within a closed museum in the evening, and interact with their audience creating brand awareness.

- Performative approach: Linked to the local strategy implemented by the involved public body. The performative approach is genuinely local, although put into practice in various ways and at different levels. Eventually, the development of the factor 'cultural newsjacking' is also similar between the two countries.

While the main crucial differences between the two countries can be reported as: 
- Interaction: In The Netherlands, influencer marketing's privileged (even monopolising) tool can be identified in the social platform Instagram escalating use of this social platform among young users (Oostveer, 2018, 2019). While, in Italy, Instagram is less widespread than in The Netherlands and with a lower increase by the year. $57 \%$ of Italian museums are currently active on social media, in particular, their presence on Instagram grows (Osservatorio, 2018), but it happens at a slower pace and in a disproportionate way, compared to The Netherlands.

- Visual popularisation: In The Netherlands, the result-oriented approach lying underneath the marketing choices leads to the use of both micro-influencers, but also of Instagrammers with many followers, like, e.g., Museum Voorlinden, with a mainly aesthetical approach. In Italy, the choice is oriented towards micro-influencers of local origin, and to popular influencers who have a personal relationship with the city of the museum but who, at the same time, are much appreciated for the quality of their content and the debunking approach.

\section{Discussion and conclusions}

Influencer marketing has been emerging all over the world as an essential strategy for different sectors, reaching importance also in cultural settings such as museums. The present paper contributes to shedding light on the differences in influencer marketing strategies in different countries, and it could be beneficial to improve the overall performance of nations having different heritage resources and approaches to marketing such as Italy and The Netherlands. Italy and The Netherlands represent two different realities which, however, have also closer aspects.

The present work does not investigate single influencer marketing strategies, but it studies some components (interaction, creativity, visual popularisation, cultural newsjacking, performative approach) to analyse these features in different countries. The research outcomes show that all the framework dimensions of the influencer marketing model that is assumed as the theoretical basis for the current analysis include several local elements impacting on the development and implementation of influencer marketing. Specifically, there are differences and similarities in the two countries, as discussed above, that museums should take into consideration in developing and implementing influencer marketing strategies.

The aim is at contributing to the literature gap, both considering theoretical and the practical side of the implementation of influencer marketing in the museum field. The analysis of Italian and Dutch realities supports the research hypothesis. Moreover, the results mentioned above can be generalised to other countries. In other words, the components of the framework can be used as investigation canvas and applied to other geographical areas and contexts. In other terms, the results are not limited to these countries but are relevant also for other countries.

This taxonomy permits to respond to the research questions, emerging that the influencer marketing strategy has peculiar local features as well as more general ones. Therefore, there is no single way all over the world to implement these strategic approaches in the museums; even if some aspects are standard, it is crucial to consider the different culture, needs, and features of each country even if both are in Europe. 
Despite its contribution to the existing literature on influencer marketing strategies, this paper does not face some topics out of scope but interesting for future scientific contributions.

This research does not aim at delivering practical suggestions for best practices in implementing influencer marketing strategies in museums or other related cultural settings. However, it strives to deepen the knowledge of this tailored marketing strategy which is increasingly useful for practitioners' discussion. For example, the findings of the research suggest that in creating a marketing strategy, museums should consider the role of influencers and, precisely, should follow a context-based approach, as well as capture more general trends and attitudes. Besides, in all the countries, influencer marketing strategies are at the beginning and, thus, not completely implemented, or their outcomes are still not measured adequately to be assessed. Even if the scope of the present paper is not their success or failure, but rather the different drivers of those strategies, it can be suggested to consider the components of the framework as a label to get a deeper insight into the implementation and development of influencer marketing.

These results have important implications for practitioners and future scholarly research alike. Further studies could deepen the analysis comparing more countries in the same or different geographic areas with a multi-nation approach or using a case-based approach to further investigate on this crucial and innovative marketing strategy. Indeed, some key factors seem to affect the implementation of influencer marketing for museums as a BM. For example, in The Netherlands, a more bottom-up approach is expected but boosted by the municipality, within a centralised overall vision embodied by the State. While in Italy, a bottom-up and scattered approach is more likely to be expected, due to both discontinuity of political decision and the massive disproportion between performance-oriented and skilled museums on the one hand, and under-skilled and non-performing museums on the other hand.

\section{References}

Abidin, C. (2014) '\#In\$tagLam: Instagram as a repository of taste, a burgeoning marketplace, a war of eyeballs', in Berry, M. and Schleser, M. (Eds.): Mobile Media Making in an Age of Smartphones, Palgrave Pivot, New York

Abidin, C. (2016) 'Visibility labour: engaging with influencers' fashion brands and \#OOTD advertorial campaigns on Instagram', Sage Journal, Vol. 16, No. 1, p.86.

AdresData (2018) Museum Overzicht 2018 [online] https://www.em-cultuur.nl/museum-overzicht2018/ (accessed 12 March 2019).

Arostegui, J.A.R. and Rius-Ulldemolins, J. (2018) 'Cultural policies in the South of Europe after the global economic crisis: is there a Southern model within the framework of European convergence?', International Journal of Cultural Policy, DOI: 10.1080/ 10286632.2018 .1429421$.

Austin, J.L. (1962) How To Do Things With Words, Harvard Univ. Press, Cambridge, MA.

Barry, J. (2014) 4 Archetypes of Top Social Media Influencers [online] http://blog.socialcontentmarketing.com/top-social-media-influencers/ (accessed 12 March 2019).

Bladow, R. and Mary, L.R. (2017) Worth the Click: Why Greater FTC Enforcement Is Needed to Curtail Deceptive Practices in Influencer Marketing, HeinOnline, Williamsburg, VA, USA.

Bryman, A. and Bell, E. (2011) Business Research Methods, Oxford University Press, Oxford.

Bryman, A. and Burgess, B. (2002) Analyzing Qualitative Data, Routledge, New York. 
Budge, K. (2017) 'Objects in focus: museum visitors and Instagram, Curator', The Museum Journal, Vol. 60, No. 1, pp.67-85.

CBS (2016) Musea in Nederland 2016, Paper of the Dutch Institute of Statistics [online] https://www.cbs.nl/nl-nl/achtergrond/2017/44/musea-in-nederland-2016 (accessed 12 March 2019).

Cialdini, R.B. (1998) 'Social influence: social norms, conformity, and compliance', in Gilbert, D.T., Fiske, S.T., Lindzey, G. and Aronson, E. (1998): The Handbook of Social Psychology, 4th ed., Oxford University Press, Boston, MA.

Cialdini, R.B. (2007) Influence: The Psychology of Persuasion, Imprint of HarperCollins, New York.

Cialdini, R.B. and Goldstein, N.J. (2004) 'Social influence: compliance and conformity', Annual Review of Psychology, Vol. 55, No. 1, pp.591-621.

Corbin, J.M. and Strauss, A. (1990) 'Grounded theory research: procedures, canons, and evaluative criteria', Qual. Sociol., Vol. 13, No. 1, pp.3-21.

De Smit, M. (2018) Musea Zoeken Millennial, Die Weer Een Leuk Plaatje Voor Insta Zoekt [online] https://nos.nl/op3/artikel/2252985-musea-zoeken-millennial-die-weer-een-leukplaatje-voor-insta-zoekt.html (accessed 13 February 2019).

De Veirman, M., Cauberghe, V. and Hudders, L. (2017) 'Marketing through Instagram influencers: the impact of number of followers and product divergence on brand attitude', International Journal of Advertising, Vol. 36, No. 5, pp.798-828, DOI: 10.1080/02650487.2017.1348035.

Duong, P. (2017) What Is Influencer Marketing? - The 2018 New Definition [online] https://blog.influencerdb.com/influencer-marketing-definition-2018/ (accessed 12 March 2019).

EHV365 (2016) Strategie 2016-2020, Whitepaper [online] https://www.eindhoven365.nl/_ asset/_public/Strategie-2020.pdf.

Ercolano, S., Gaeta, G.L. and Parenti, B. (2018) 'Pompeii dilemma: a motivation-based analysis of tourists' preference for 'superstar' archaeological attractors or less renowned archaeological sites in the Vesuvius area', Int. J. Tourism Res., Vol. 20, pp.345-354 [online] https://doi.org/10.1002/jtr.2186.

Ewers, N.L. (2017) \#sponsored - Influencer Marketing on Instagram. An Analysis of the Effects of Sponsorship Disclosure, Product Placement, Type of Influencer and their Interplay on Consumer Responses, Master thesis, University of Twente.

Ferraro, V. (2011) 'Restyling museum role and activities: European best practices towards a new strategic fit', Journal of the Department of Cultural Heritage, No. 2, University of Macerata [online] http://dx.doi.org/10.13138/2039-2362/99.

Firpo, E. (2015) The Birth of \#EmptyMuseo in Rome [online] https://fathomaway.com/emptymuseo-instagram-project/ (accessed 6 March 2019).

Galleria Nazionale (2019) La Galleria Nazionale Report 2018 [online] https://issuu.com/ lagallerianazionale/docs/report_2018_-_rev_07/190 (accessed 15 March 2019).

Glaser, B.G. and Strauss, A.L. (2017) Discovery of Grounded Theory: Strategies for Qualitative Research, Routledge, London.

Glucksman, M. (2017) 'The rise of social media influencer marketing on lifestyle branding: a case study of Lucie Fink', Elon Journal of Undergraduate Research in Communications, Vol. 8, No. 2, pp.77-87.

Gross, J. and Wangenheim, F.V. (2018) 'The big four of influencer marketing. A typology of influencers', Marketing Review St. Gallen, Vol. 2, No. 2, pp.30-38.

Gürkaynak, G., Kama, Ç.O. and Ergün, B. (2018) 'Navigating the uncharted risks of covert advertising in influencer marketing', Business Law Review, Vol. 39, No. 1, pp.17-19.

Hamel, G. (2000) Leading the Revolution, Plume, New York.

Hammersley, M. (1997) 'Qualitative data archiving: some reflections on its prospects and problems', Sociology, Vol. 31, No. 1, pp.131-142. 
Hellenkamper, M. (2019) State of the Industry - Influencer Marketing in 2019 [online] https://blog.influencerdb.com/state-of-the-industry-influencer-marketing-2019/ (accessed March 2019).

Ioanid, A., Militaru, G. and Mihai, P. (2015) 'Social media strategies for organisations using influencers' power', European Scientific Journal, Special Edition 2015, pp.139-143.

ISTAT (2016) I Musei, le Aree Archeologiche e i Monumenti in Italia, Report of the Italian Institute of Statistics [online] http://www.istat.it (accessed 20 February 2019).

Jaakonmäki, R., Müller, O. and vom Brocke, J. (2017) 'The impact of content, context, and creator on user engagement in social media marketing', Proceedings of the 50th Hawaii International Conference on System Sciences.

Johansen, I.K. and Guldvik, C.S. (2017) Influencer Marketing and Purchase Intentions. How does Influencer Marketing Affect Purchase Intentions?, PhD thesis, Norwegian School of Economics.

Join (2019) Influencers Uit de Kunst: Influencer Marketing in Musea [online] https://join.marketing/nl/2018/influencer-marketing-musea/\#/ (accessed 12 March 2019).

Kickert, W.J.M. (1997) 'Public governance in The Netherlands: an alternative to Anglo-American 'managerialism', Public Administration, Vol. 75, No. 4, pp.731-752, Wiley.

Kirezli, O. (2011) 'Museum marketing: shift from traditional to experiential marketing', International Journal of Management Cases, Special Issue: CIRCLE Conference, No. 12, pp.173-184.

Kolb, D. (2000) 'Learning places: building dwelling thinking online', Journal of Philosophy of Education, Vol. 34, No. 1 [online] https://doi.org/10.1111/1467-9752.00160.

Lollo, L.V. (2018) City Branding for Tourism: The Power of Image Selection, PhD dissertation, Radboud University, Nijmegen.

Lyotard, J-F. (1984) The Postmodern Condition: A Report on Knowledge, Translated by Geoffrey Bennington and Brian Massumi, Univ. of Minnesota Press, Minneapolis.

Manetti, G. (2011) 'The quality of stakeholder engagement in sustainability reporting: empirical evidence and critical points', Corporate Social Responsibility and Environmental Management, Vol. 18, No. 2, pp.110-122.

Mays, N. and Pope, C. (1995) 'Rigour and qualitative research', Br. Med. J., Vol. 311, No. 6997, p.109.

Navarrete, T. (2014) 'Becoming digital: a Dutch heritage perspective', The Journal of Arts Management, Law, and Society, Vol. 44, No. 3, pp.153-168, DOI: 10.1080/ 10632921.2014.938385.

Nielsen (2015) Recommendations From Friends Remain Most Credible Form of Advertising Among Consumers; Branded Websites Are the Second-Highest-Rated Form [online] https://www.nielsen.com/eu/en/press-room/2015/recommendations-from-friends-remain-mostcredible-form-of-advertising.html (accessed 5 March 2019).

Oostveer, D. (2018) Social Media in Nederland 2018: Uittocht Van Jongeren op Facebook [online] https://www.marketingfacts.nl/berichten/jongeren-keren-facebook-massaal-de-rug-toe (accessed 27 February 2019).

Oostveer, D. (2019) Social Media in Nederland 2019: Facebook Verliest Ruim Half Miljoen Gebruikers [online] https://www.marketingfacts.nl/berichten/social-media-in-nederland-2019facebook-verliest-meer-dan-een-half-miljoen (accessed 13 March 2019).

Osservatorio (2018) I musei visti dal Web nel 2018, Osservatorio Innovazione Digitale nei Beni e Attività Culturali, Politecnico di Milano, Milan.

Osterwalder, A., Pigneur, Y. and Tucci, C. L. (2005) 'Clarifying business models: origins, present and future of the concept', Communications of the Association for Information Science (CAIS), Vol. 16, pp.1-25.

Pecorelli, C. (2017) La Nuova Gestione Dei Musei: Il Caso Particolare Della Galleria Nazionale di Roma, MA thesis, 2016/2017, Università Ca' Foscari di Venezia, Venice. 
Petkus Jr., E. (2004) 'Enhancing the application of experiential marketing in the arts', Non Profit and Voluntary Sector Marketing, Vol. 9, No. 1, pp.49-56.

Platteeuw, E. (2018) Influencers \& musea: topbereik met klein budget [case] [online] https://www.frankwatching.com/archive/2018/03/08/influencers-musea-topbereik-met-krapbudget-case/ (accessed 12 March 2019).

Prentice, R. (2001) 'Experiential cultural tourism: museums \& the marketing of the new romanticism of evoked authenticity', Museum Management and Curatorship, Vol. 19, No. 1, pp.5-26, DOI: 10.1080/09647770100201901.

Profili (2018) I Giovani a Spasso per i Musei: La Fortunata Collaborazione Tra Card Musei Bologna e Luis Sal [online] https://www.profili.eu/2018/06/20/i-giovani-a-spasso-per-i-museila-fortunata-collaborazione-tra-card-musei-bologna-e-luis-sal/ (accessed 26 February 2019).

Russo, F. (2018) I Musei Italiani Sono Sempre Più Sui Social Media Ma Pochi Hanno Progetti Innovativi [online] https://www.franzrusso.it/condividere-comunicare/i-musei-italiani-sonosempre-piu-sui-social-media-ma-pochi-hanno-progetti-innovativi/ (accessed 26 February 2019).

Sallami, F. (2018) Instragram per un Museo [online] https://www.telemaco.it/blog/instagram-perun-museo/ (accessed 3 March 2019).

Sammis, K., Lincoln, C. and Pomponi, S. (2016) Influencer Marketing for Dummies, John Wiley \& Sons, Inc., Hoboken, New Jersey.

Searle, J. (1969) Speech Acts: An essay in the Philosophy of Language, Cambridge Univ. Press, Cambridge, UK.

Seidel, J. and Kelle, U. (1995) 'Different functions of coding in the analysis of textual data', in Computer-aided Qualitative Data Analysis: Theory, Methods and Practice, pp.52-61, Sage, Thousand Oaks, CA.

Settels, S. (2018) Waarom Micro-Influencers Werken \& Hoe je de Perfecte Match Vindt [online] https://www.frankwatching.com/archive/2018/04/16/waarom-micro-influencers-werken-hoeje-de-perfecte-match-vindt/ (accessed March 2019).

Stevenson, D., Balling, G. and Kann-Rasmussen, N. (2017) 'Cultural participation in Europe: shared problem or shared problematisation?', International Journal of Cultural Policy, Vol. 23, No. 1, pp.89-106, DOI: 10.1080/10286632.2015.1043290

Stroia, P. (2016) I Musei Italiani Migliorano con Travel Appeal [online] https://www.travelappeal.com/it/musei-italiani-migliorano-con-travel-appeal/ (accessed 9 March 2019).

Tham, A., Croy, G. and Mair, J. (2013) 'Social media in destination choice: distinctive electronic word-of-mouth dimensions', Journal of Travel \& Tourism Marketing, Vol. 30, Nos. 1-2, pp.144-155, DOI: 10.1080/10548408.2013.751272.

Turner, B.A. (1981) 'Some practical aspects of qualitative data analysis: one way of organizing the cognitive processes associated with the generation of grounded theory', Qual. Quant., Vol. 15, No. 3, pp.225-247.

US News (2019) [online] https://www.usnews.com/news/best-countries/influence-rankings (accessed 10 March 2019).

Van den Elsen, F. (2018) Influencer Marketing $x$ Culturele Sector = Match Made in Heaven [online] https://www.frankwatching.com/archive/2018/01/10/influencer-marketing-x-culturele -sector-match-made-in-heaven (accessed 3 March 2019).

Vermeeren, A.P.O.S., Calvi, L., Sabiescu, A., Trocchianesi, R., Stuedahl, D. and Giaccardi, E. (2016) 'Involving the crowd in future museum experience design', Proceedings of the 2016 CHI Conference Extended Abstracts on Human Factors in Computing Systems [online] https://doi.org/10.1145/2851581.2856482.

Weilenmann, A., Hillman, T. and Jungselius, B. (2013) 'Instagram at the museum: communicating the museum experience through social photo sharing', Chi 2013: Changing Perspectives, Paris, France, 27 April-2 May. 
Woods, S. (2016) \#Sponsored: The Emergence of Influencer Marketing, University of Tennessee Honors Thesis Projects [online] https://trace.tennessee.edu/utk_chanhonoproj/1976 (accessed 25 February 2019).

Yin, R.K. (2013) Case Study Research: Design and Methods, Sage Publications, Thousand Oaks, CA.

Zardini, A., Rossignoli, C., Mola, L. and De Marco, M. (2014) 'Developing municipal e-government in Italy: the city of Alfa case', in International Conference on Exploring Services Science, Springer, Cham, pp.124-137.

Zietek, N. (2016) Influencer Marketing - The Characteristics and Components of Fashion Influencer Marketing, Thesis for one-year Master in Textile Management, The Swedish School of Textiles, University of Borås.

Zott, C., Amit, R. and Massa, L. (2011) 'The business model: recent developments and future research', Journal of Management, Vol. 37, No. 4, pp.1019-1042. 